\title{
DOS MENINOS ITALIANOS AOS CANILLITAS DA LUCIÉRNAGA: O PRIMEIRO STREET PAPER DA AMÉRICA LATINA
}

\author{
SUZANA ROZENDO BORTOLI \\ Universidade de São Paulo \\ São Paulo, Brasil \\ E-mail: suzanarozendo@usp.br
}


DOS MENINOS ITALIANOS AOS CANILLITAS DA LUCIÉRNAGA: O PRIMEIRO STREET PAPER DA AMÉRICA LATINA

Resumo: O presente trabalho deriva de uma dissertação de mestrado em Jornalismo e abarca a trajetória da revista La Luciérnaga, o primeiro street paper que surgiu na América Latina. Elege-se como objetivo principal analisar a relação desse produto jornalístico com as transformações sociais de jovens em situação de rua de Córdoba, e como objetivo secundário traçar um paralelo dos primeiros vendedores de jornais - que eram meninos italianos - com os canillitas.

Palavras-chave: La Luciérnaga; street papers; canillitas.

FROM ITALIAN BOYS TO THE CANILLITAS OF LUCIÉRNAGA: THE FIRST STREET PAPER IN LATIN AMERICA

Abstract: This article results from a Journalism dissertation and covers the history of the magazine La Luciérnaga, the first street paper in Latin America. We elect as main objective analyze the relationship of this journalistic product with the social transformations of youth homeless of Cordoba (Argentina), and as a secondary objective to make a parallel of the first newspaper sellers - that were Italian boys - with the canillitas.

Keywords: La Luciérnaga; street papers; canillitas.

DESDE CHICO ITALIANOS A LOS CANILLITAS DE LUCIÉRNAGA: EL PRIMER PERIÓDICO DE LA CALLE EN AMÉRICA LATINA

Resumen: Este trabajo es el fruto de una disertación de maestria en Periodismo y habla de la historia de la revista La Luciérnaga, el primer periódico de la calle de la América Latina. Eligimos como principal objetivo analizar la relación de este producto periodístico con las transformaciones sociales de jovenes en situación de calle de Córdoba, y, cómo objetivo secundario, establecer un paralelismo de los primeros vendedores de periodicos - que eran niños italianos - con los canillitas.

Palabras clave: La Luciérnaga; street papers; canillitas. 


\section{OS STREET PAPERS NA AMÉRICA LATINA}

Os street papers são revistas ou jornais vendidos por pessoas em situação de rua em todos os continentes do mundo. Para o produto ser considerado como tal, é necessário que seja filiado à International Network of Street Papers, cuja sede é na Escócia, e que seja comercializado, exclusivamente, por pessoas em situação de risco social - e não em bancas de revista ou por assinatura. Os vendedores atuam sob a regência de um código de conduta e recebem um treinamento específico, além disso, usam uniformes e crachás de identificação. Uma porcentagem do lucro vai para o vendedor e a outra para os custos de manutenção das organizações responsáveis.

A história desses produtos editoriais teve início no final da década de 1980, devido ao crescente número de desabrigados em Nova lorque', com o lançamento do jornal Street News. A empreitada serviu de inspiração para a revista The Big Issue, de Londres, em 1991, cujos objetivos principais eram gerar renda aos desabrigados e elevar a autoestima deles. Com o sucesso do empreendimento da Big Issue, o método passou a ser replicado em outras grandes cidades e, atualmente, existem 100 propostas diferentes em mais de 40 países do mundo².

O primeiro trabalho fora da Grã Bretanha foi lançado em l994, em São Petersburgo, na Rússia. Depois, o projeto foi implantado em Melbourne, na Austrália e na Cidade do Cabo, África do Sul (HANKS; SWITHNBANK, 1997). Assim, foram surgindo outros street papers na Ásia, África e América, a fim de auxiliar sujeitos considerados excluídos socialmente e inseri-los no mundo do trabalho.

Em 1995, foi inaugurado o primeiro street paper da América Latina, a La Luciérnaga, em Córdoba, na Argentina, país que também conta com a revista Al Margen, de Bariloche e a Hecho en Buenos Aires, da capital. Além dessas publicações, há a revista La Calle, de Bogotá, que se iniciou na Colômbia, em 2007, e a revista La Callejera, do Uruguai. No Brasil, o jornal Boca de Rua, de Porto Alegre, foi o primeiro street paper a dar voz às pessoas em situação

\footnotetext{
$1 \mathrm{Em}$ abril de 2012, Nova lorque atingiu o recorde de 43 mil sem-teto, sendo 17 mil crianças. Mesmo depois de 23 anos do surgimento dos street papers, a cidade ainda não tem um programa que ofereça alternativas para as famílias em situação de emergência. Disponível em:< http://www1.folha.uol.com.br/mundo/1102310-nova-york-atinge-recorde-de-43-mil-sem-teto-em-refugios.shtml>. Acesso em: 20 jul. 2012.
}

2 Disponível em: <http://www.street-papers.org/>. Acesso em: 23 jul. 2012. 
de rua, em 1999. Em 2002, foi concretizada a Ocas", revista que circula em São Paulo e no Rio de Janeiro e, por último, em 2006, surgiu o jornal Aurora da Rua, de Salvador.

\section{LA LUCIÉRNAGA: A LUZ QUE PISCOU PRIMEIRO}

A revista La Luciérnaga (tradução: o vagalume) ou apenas La Luci, como carinhosamente é conhecida, foi idealizada pelo psicólogo Oscar Arias. A publicação faz parte de um conjunto de atividades de uma fundação, que leva o mesmo nome 3 .

Há 17 anos em circulação, o projeto editorial surgiu no dia 20 de julho de 1995 como uma reação a um descumprimento do governo de Córdoba. Para Roxana Albrecht (2009, p.29, tradução nossa), a revista “emerge como um projeto participativo em um ambiente sociopolítico, onde se instala e se aprofunda o modelo neoliberal de Estado, que promove como política social o assistencialismo ${ }^{\prime \prime}$. Segundo a autora, nessa época, as ruas do centro da capital de Córdoba estavam cheias de vendedores ambulantes, grupos de adolescentes que esperavam os carros frearem no semáforo para limpar os para-brisas, crianças mendigando mesa por mesa nos bares e mães instaladas com suas famílias nas portas de igrejas e supermercados.

De acordo com Oscar Arias, em 1994 foi criado o Programa de Prevención para Chicos en Situación de Calle para selecionar meninos e meninas maiores de 16 anos que trabalhavam como limpadores de vidro de carro para capacitação de ofícios do mercado formal. Dessa maneira, além de serem (re) inseridos socialmente e obterem uma renda fixa, eles não seriam discriminados pela sociedade, nem perseguidos pela polícia. O trabalho seria realizado em meios de comunicação, pois isso seria um estímulo para que os jovens analfabetos voltassem aos estudos. Dos 40 inscritos no Programa, oito foram

3 Situada à Avenida Vélez Sarsfield, n. 1180, Córdoba, a Fundação funciona em uma grande casa alugada, com várias salas onde se realizam os atendimentos, um refeitório com capacidade para 300 pessoas e um campo de futebol. Na Fundación La Luciérnaga existe um restaurante que serve café da manhã e almoço aos participantes, há tratamento para dependentes químicos, atendimentos psicológico e odontológico, consultoria jurídica, farmácia popular, cursos de capacitação, assistência para aquisição de moradia, documentos e empregos formais aos que completam 25 anos.

4 Texto original: emerge como un proyecto participativo en un entorno sociopolítico donde se instala y profundiza el modelo neoliberal de Estado, que promueve como política social el asistencialismo. 
selecionados. Nas palavras de Arias:

Estava tudo certo, mas, nesta época, a Argentina estava passando por uma enorme crise econômica, chamada "Efeito Tequila5". O governador de Córdoba teve que renunciar porque não estava dando conta de pagar o salário dos funcionários públicos e muito menos a bolsa dos meninos de rua que foram selecionados para trabalhar. Isso foi uma grande frustração pra mim (informação verbal).

Diante dessa frustração, Arias conheceu o trabalho da revista Big Issue, de Londres, e percebeu naquela proposta um grande potencial para transformação social de pessoas marginalizadas. Sendo assim, recrutou os selecionados do Programa para fundar um projeto semelhante em Córdoba, focado em jovens em situação de rua. Com o apoio de um empresário do ramo de comunicação, no dia 20 de julho de 1995 foi veiculada a primeira revista, em preto e branco, tamanho $\mathrm{A}_{5}$, com tiragem de dois mil exemplares, ao custo de 0,50 pesos 7 .

O projeto foi prontamente aceito pela população cordobesa e, com o passar dos anos, a tiragem e o número de vendedores foram aumentando. "O resultado econômico imediato para os meninos era uma forte atração da atividade, em poucas horas, eles ganhavam o mesmo do que quando levavam o dia todo limpando para-brisas" "(ALBRECHT, 2009, p. 37, tradução nossa).

Em junho de 2012, foram 20 mil exemplares impressos, em tamanho A4 e colorido, vendidos a oito pesos por 70 vendedores de 18 a 25 anos em Córdoba, Río Cuarto, Alta Gracía, Mina Clavero, e San Francisco. Eles ficam com \$4,50 de lucro e utilizam uma parcela desse total para adquirir novas publicações. Vale mencionar que, no ano 2000, começou a ser realizada a produção regionalizada do projeto editorial, ou seja, na revista produzida na capital são agregadas folhas centrais com assuntos da problemática local (ALBRECHT, 2009, p.56). Em anos anteriores, um volume de 30 mil revistas

5 Efeito Tequila foi o nome que se deu à crise econômica que começou no México, em 1994, e afetou outros países. Nesse ano, a província de Córdoba estava nas mãos do governador Eduardo Angelóz.

6 Entrevista concedida à autora em 20 de junho de 2012, na sede da Fundación La Luciérnaga, em Córdoba, Argentina.

7 Equivalente a R\$ 0,25, em junho de 2012.

8 Texto original: El resultado económico inmediato para los chicos fue un fuerte atractivo de la actividad, en pocas horas hacían lo que les llevaba todo el día limpiando parabrisas. 
vendido por 350 canillitas - ou luciérnagos, apelidos dados aos vendedores da Luciérnaga - chegou a circular na província de Córdoba.

O nome da revista metaforiza a luz e seu slogan é Revista Cultural de los chicos trabajadores de la calle. Segundo Arias, os vagalumes fabricam sua própria claridade e andam sempre em grupos. "Aqui é da mesma forma, os jovens podem fabricar sua própria energia e nós estimulamos o trabalho coletivo" (informação verbal). A publicação não recebe subsídio do Estado e se sustenta com recursos próprios, com o patrocínio de lojas, supermercados, construtoras, restaurantes, escolas e com o trabalho em rede de outras instituições. Além disso, há o apoio de universidades e parte do conteúdo da revista é feita pela comunidade acadêmica. "Ao mesmo tempo em que eles nos patrocinam, gostam de escrever para a revista. Na Argentina, isso se chama 'responsabilidade social universitária'”, ressalta o fundador da revista.

$\mathrm{Na}$ edição de dezembro de 2011, Rafael Velasco, reitor da Universidade Católica de Córdoba, ao ser questionado por que apoia o projeto, responde:

\begin{abstract}
A Luciérnaga oferece oportunidades reais a jovens que lutam para escapar do círculo vicioso da desigualdade em que nós como sociedade os colocamos. É bem verdade que a injustiça, a inequalidade e a exclusão são responsabilidade direta de governos ineficientes, quando não inoperantes. Nós cidadãos também temos nossa parcela de responsabilidade na discriminação, no estigma - e todo mundo sabe o quanto - na hora de pensar em determinadas decisões ${ }^{9}$ (VELASCO, 2011, p.3, tradução nossa).
\end{abstract}

Em 17 anos de existência, Oscar Arias revela que o maior mérito da revista foi ter tirado jovens da extrema pobreza para ajudá-los a se transformar em adultos classe média, além de ter impulsionado a mudança da opinião pública acerca dos meninos de rua. No entanto, o projeto sempre enfrentou (e ainda enfrenta) muitos desafios:

Passam coisas lindas aqui, mas também há coisas espantosas. Lutar contra as drogas é um dos maiores obstáculos. A droga é o que mais retrocede nosso trabalho e ela sempre existe entre os jovens que vivem em situação de rua. Colocar de pé uma pessoa que tem

9 Texto original: La Luciernaga les brinda oportunidades reales a jóvenes que luchan por salir del círculo vicioso de desigualdad en el que los hemos colocado como sociedad. Ya que se bien es verdad que la injusticia la inequidad y la exclusión son responsabilidad directa de gobiernos ineficaces, cuando no inoperantes, también los ciudadanos tenemos nuestra responsabilidad en la discriminación, la estigmatización - y cada uno sabe cuánto - a la hora de pensar determinadas decisiones. 
muitos problemas leva tempo: um, dois, três anos. Em dois meses de vício, perdemos todo o trabalho que fizemos antes. O canillita se droga, comete um delito e vai preso ou morre pelos traficantes. Houve pessoas que chegaram aqui armadas, em meio a uma crise psicótica, porque foram presas antes e achavam que o projeto era uma prisão. Tivemos problemas com rixas de meninos que queriam brigar aqui dentro. Eles não chegam como anjinhos, eles têm crises, ficam bravos, descontam seus problemas em alguém que trabalha aqui. Conviver com essa violência é algo difícil, mas o maior desafio foi conseguir uma boa equipe de trabalho (informação verbal).

\section{A REVISTA, POR PARTES}

A Luciérnaga surgiu com a perspectiva de que os vendedores, juntamente com uma equipe técnica, fossem os reais produtores de conteúdo. Nos dias atuais, não é assim que funciona, embora Arias reforce que os canillitas são os protagonistas da publicação.

Temos uma oficina de escrita, na qual os canillitas aprendem a escrever para a revista. No entanto, nem sempre dá certo. Primeiro porque é necessário ter dinheiro para pagar um professor que assuma o compromisso de ensiná-los. E para que saia alguma coisa "publicável”, leva-se tempo, uns três meses. Já fizemos uma revista inteira assim, escrita $80 \%$ pelos meninos. Mas se a revista for sempre escrita pelos luciérnagos, ela se tornará meio previsível e, para poder vender, ela precisa despertar o interesse dos compradores. Atualmente, o que nunca pode faltar é a seção Histórias de Vida, na qual um dos participantes conta sua história de verdade e não uma versão estereotipada. Isso, sim, nós acreditamos que seja participação e os meninos disputam para aparecer na revista! Eles contam de onde vêm e como tratam de superar seus problemas. Com isso, queremos que as pessoas acreditem neles e que eles sirvam de exemplo ao ensinar como fabricam sua própria luz (informação verbal).

Albrecht (2009) afirma que nessas oficinas realizadas em anos anteriores, os jovens pesquisavam fontes, gravavam as entrevistas, transcreviam-nas, redigiam e editavam as reportagens. Dessa maneira, estavam imersos em um processo gradual de aprendizagens, distribuíam responsabilidades e exerciam seu poder de decisão:

Para garantir conteúdos de "qualidade" são incorporadas entrevistas com artistas, escritores, políticos e outros personagens socialmente reconhecidos, além de publicar notas de jornalistas e escritores de renome. Todo este material ocupa o espaço que estava previsto para que os 
jovens a expressassem suas opiniões e mundo de sentidos ${ }^{10}$ (ALBRECHT, 2009, p.110, tradução nossa).

Por outro lado, o protagonismo dos jovens ao qual se refere Oscar Arias consiste em colocá-los em destaque nas matérias de capa e serem ouvidos como fontes das reportagens. Exemplo desta participação foi o depoimento de Emanuel Vargas em História de Vida (Figura 1), na edição de junho de 2011, na qual confessou que para não ver sua família passar fome, muitas vezes se drogava e criava coragem para "bater carteira", por isso, foi preso várias vezes. A relação com o trabalho de canillita lhe serviu de estímulo para iniciar um tratamento de saúde:

A droga é um lixo. Graças a Deus estou deixando-a quase por completo. Me falta pouco. Mas não se pode deixar de repente. Às vezes fumo maconha, mas já deixei a cocaína e as anfetaminas. A gente se torna escravo e não consegue ocupar a cabeça com outra coisa a não ser voltar a consumir e assim podem se passar anos inteiros (LA LUCIERNAGA, 2012, p.5).

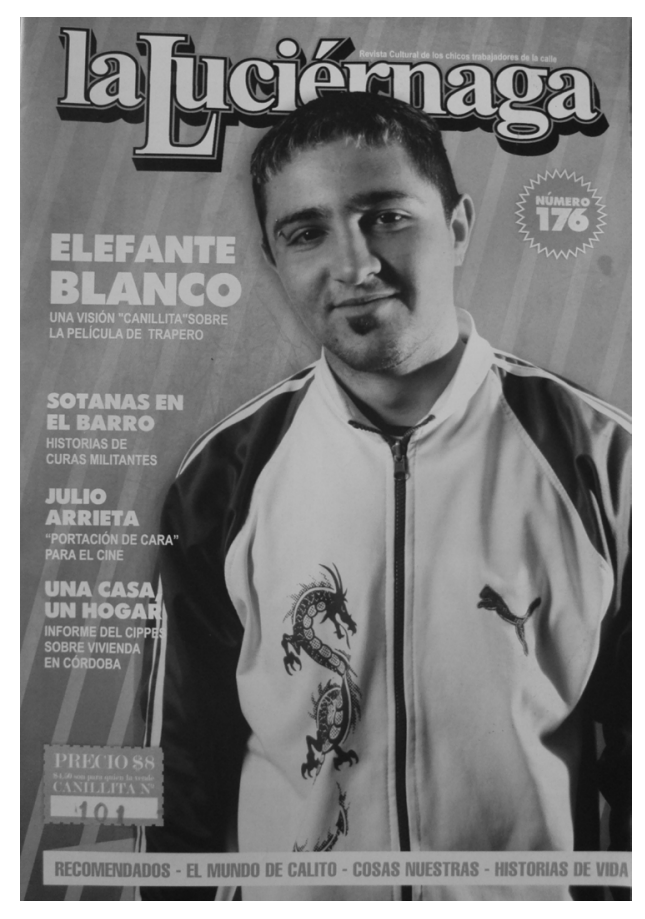

Figura1: Emanuel Vargas na capa da edição de junho de 2012

10 Texto original: Para procurar contenidos de "calidad" se incorporan entrevistas a artistas, escritores, políticos y otros personajes reconocidos socialmente, además de publicar notas de periodistas y escritores de renombre. Todo este material ocupa el espacio que estaba previsto para que los jóvenes expresen sus opiniones y mundo de sentidos. 
Ainda, distintas formas de participação indireta aparecem em outras seções. A Historieta, por exemplo, é um recurso que conta sobre o mundo de Calito, um personagem criado para narrar os fatos cotidianos que os luciérnagos contam na sede da Fundação.

A publicação sempre apresenta um artigo de investigação jornalística, que fala sobre temas que geram grandes discussões, como o tráfico de muIheres, os sem-terra do Brasil, a diminuição da maioridade penal, a prostituição infantil, os estudantes desaparecidos durante a sanguinolenta ditadura militar da Argentina, a rebelião estudantil para educação pública no Chile etc.

Há a seção Amigos de La Luciérnaga, onde é divulgado o trabalho dos artistas que ajudam nas campanhas do projeto. Na Cosas Nuestras, aparecem as novidades dos vendedores, dos voluntários e dos eventos que envolvem a revista. Nesta coluna, há um box com os seguintes dizeres:

A Luciérnaga é muito mais que uma revista, é um lugar cheio de vida. É um grupo cheio de inquietudes entregue à aventura de resistir, de crescer e ser feliz. Nunca sozinhos, sempre somando amigos. Sempre sabendo que podemos ser melhores, com muita potência de trabalho"11" (COSAS NUESTRAS, 2012, p.22).

Há também um espaço para Literatura, escrito por colaboradores e outro chamado Para Agendar, com dicas de livros, teatros, cd e cursos.

A fim de estreitar os laços com seus leitores, assim como em outros veículos de comunicação, periodicamente, são realizadas análises com a intenção de melhorar a qualidade do produto. Em 2004, por exemplo, em uma pesquisa elaborada pela Consultora Perspectivas Sociales com 240 entrevistados maiores de 18 anos da cidade de Córdoba, 55,3\% havia lido a revista alguma vez, sendo a porcentagem de mulheres significativamente maior que a de homens (TROCELLO, 2005, p.21).

A pesquisa revelou ainda que os leitores preferiam ver pessoas a desenhos nas capas, além de gostarem de assuntos alegres. "Podemos falar de coisas tristes, mas a maneira de dizer não pode ser triste. Antes fazíamos matérias que apunhalavam, então, eliminamos a linha editorial da tristeza, mas não deixamos de dizer coisas duras", explica Oscar Arias.

11 Texto original: La Luciérnaga es mucho más que una revista, es un lugar lleno de vida. Es un grupo lleno de inquietudes entregado a la aventura de resistir, de crecer y ser felices. Nunca solos, siempre sumando amigos. Siempre sabiendo que podemos ser mejores, con mucha prepotencia de trabajo. 


\section{DOS MENINOS ITALIANOS AOS CANILLITAS}

No artigo "Uma história breve do jornalismo no Ocidente", Jorge Pedro de Sousa (2008) faz um percurso pela trajetória histórica do jornalismo desde a Antiguidade até o período atual. $O$ autor revela que, enquanto processo de difusão e processamento de informações noticiosas, o jornalismo teve sua forma embrionária nos moldes da Antiga Grécia e Antiga Roma.

Sousa (2008) constata que essa história começa com os fenômenos pré-jornalísticos, destacando as Atas Diurnas Romanas ${ }^{12}$, as folhas volantes, as cartas e crônicas medievais do século XVII. O autor descreve que a imprensa noticiosa pré-industrial, dos séculos XVII e XVIII, apareceu com as Gazetas.

Na América Latina, este assunto está ligado, de certa forma, à imigração italiana. Trento (1989) explica que, entre 1880 e 1940 havia um enorme número de jornais e revistas em língua italiana publicados no Brasil, sobretudo no Rio de Janeiro e em São Paulo. No entanto, não havia público para consumir estes produtos, pois a maioria dos imigrantes italianos era analfabeta ou semi-analfabeta. Além disso, aqueles que sabiam ler, devido a grande carga horária de trabalho, não tinham ânimo de se aproximar dos jornais.

As cidades, e não somente São Paulo, pululavam de um exército de engraxates, aguadeiros, vendedores de peixe ou até mesmo de castanhas assadas para não falar na profissão italiana por excelência, a de vendedor de jornais, exercida principalmente por meninos. Esses misteres vexavam muito os observadores vindo da Itália (TRENTO, 1989, p.130-1).

Além de vender os jornais descalços e com calças curtas, as crianças incomodam os transeuntes, como explica Nelson Sodré (1999) ao reproduzir a fala do jornalista Carl von Koseritz, fundador da Gazeta de Porto Alegre.

Perambulam pelas ruas milhares e milhares de rapazinhos italianos, negros e mulatos, que nos deixam quase surdos com a sua gritaria: A Galegada! Olhe a Gelegada! 100 réis a Galegada! A Defe-

12 As atas diurnas (69 a. C, Júlio Cesar) eram informações oficiais, periódicas, dos atos do povo e do senado romano. O objetivo era que a população tomasse conhecimento das leis corretamente, além disso, eram publicados casos cotidianos. As atas circulavam entre os eminentes do Império durante cinco séculos, eram lidas por romanos alfabetizados e davam origem a interpretações de toda ordem. No século XVI, essas atas reapareceram em Veneza, mas já distribuídas em cópias manuscritas, ao preço de uma gazeta, moeda local (LAGE, 2005). 
sa dos Portugueses! 100 réis A Defesa dos Portugueses! A Gazeta de notícias! 40 réis $A$ Gazeta de notícias! O Corsário, está bom $O$ Corsário. A Folha Nova, aí vai a Folha Nova! Comprem a Folha Nova ! Jornal do Comércio, 100 réis o Jornal! Cruzeiro, comprem o Cruzeiro, 40 réis o Cruzeiro! A Propaganda! Aí vai A Propaganda, etc (SODRÉ, 1999, p. 232-3).

Na Argentina, não foi diferente. Segundo José Ingenieros (1904) - que realizou uma pesquisa para a Comissão Diretiva do Círculo de Imprensa sobre trabalhos infantis na difusão de jornais - no início do século XX, havia em Buenos Aires cerca de 700 meninos vendedores de jornais (Figura 2). Metade deles pertencia ao grupo das crianças sem-teto, que eram vistas pela sociedade como perigosas e infratoras. A análise distinguia três grupos: os meninos industriais - composto por argentinos filhos de pais italianos, possuíam educação escassa, poucas noções de higiene e, em 15\% dos casos, eram os que sustentavam a família. O grupo adventício era composto por meninos de 9 a 15 anos, que viviam separados de suas famílias porque preferiam a vida isenta de obrigações e assim, rapidamente caminhavam rumo ao delito. E o último era o de delinquentes, que correspondia a $2 / 3$ dos vendedores de jornais.

O autor observou, em 1901, 500 crianças, reuniu informações das casas de menores contraventores e constatou que o ambiente em que viviam constituía a principal porta de entrada ao vício e ao crime precoce e que, portanto, deveria ser proibida a atividade de venda de jornais por menores de idade. Para Ingenieros (1904) apenas os fortes laços familiares e a dedicação sincera ao trabalho poderiam salvá-los da criminalidade. Desta forma, começou a ser construída a imagem paradigmática do menino pobre: o canillita vendedor de diários (AVERSA, 2003). 


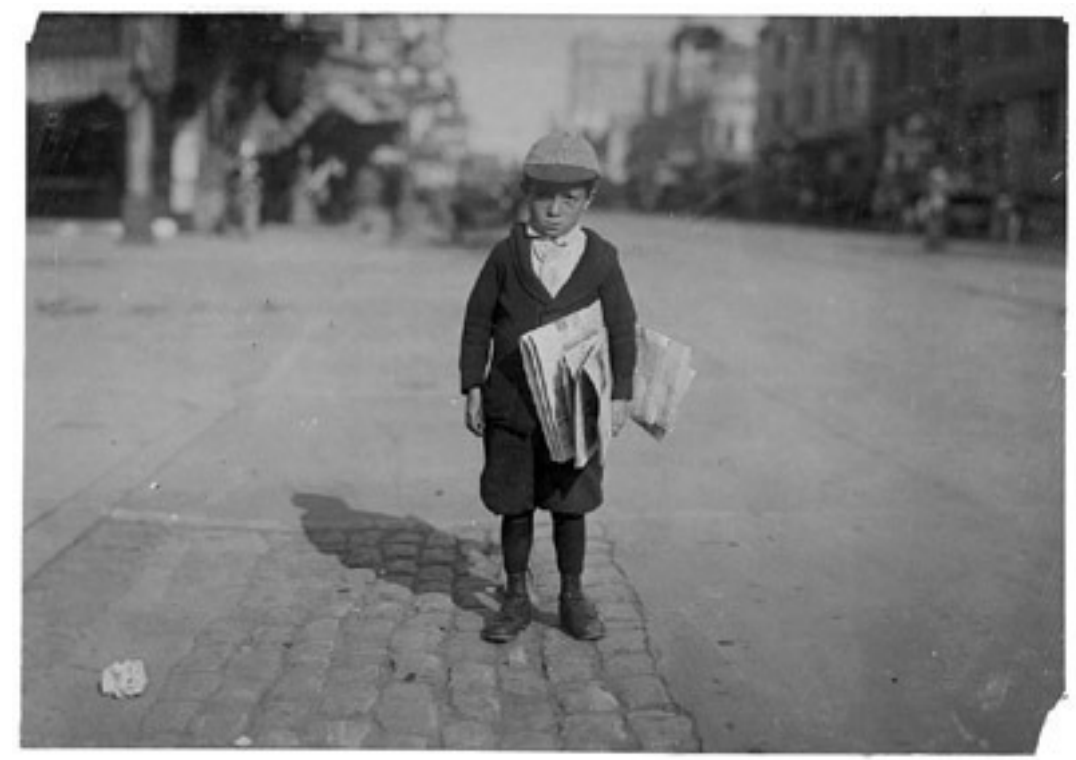

Figura 2: Os primeiros vendedores de jornais. Fonte: eblog.com

María Laura Giachino (2010) relata que, no começo do século XX, os que não conseguissem vender toda a tiragem, podiam devolvê-la aos donos de jornais e conta que o termo canillita foi utilizado pela primeira vez por um jornalista e dramaturgo uruguaio chamado Florencio Sánchez, autor da obra que leva o mesmo nome e refere-se a um dos pequenos vendedores de jornais, de pernas finas. Canillita também foi levado à tela com o filme dirigido por Lisandro de la Tea e Manuel Roneima, em 1936. Florencio Sánchez morreu no dia 7 de novembro de 1910 e desde então, nesta data, comemorase o Día del Canillita ${ }^{13}$.

Um século depois, ainda existiam semelhanças do ofício e ranços de preconceito em relação a esta atividade. Por isso, um dos objetivos da Luciérnaga foi mudar este cenário. "Eliminar o estigma de serem meninos de rua e começar a vê-los como trabalhadores de rua tem sido um bom ponto de partida que alimenta a tolerância e desativa o ressentimento que a discriminação instala nos pobres" (LA LUCIÉRNAGA, 2005, p.5).

Segundo os canillitas, trabalhando oito horas por dia, é possível conseguir uma média de três mil pesos de lucro por mês, quantia suficiente para sustentar uma casa, como relata Emanuel Vargas, de 22 anos, que começou a vender a revista aos 16 para poder levar comida a sua família. Quando seus pais perderam o emprego e não tiveram condições de pagar o aluguel, ele, o

13 Disponível em: <http://suite101.net/article/los-canillitas-pesonajes-que-hicieron-historia-a13491>. Acesso em: 24 jul. 2012. 
pai, a mãe e três irmãos mais novos tiveram que viver debaixo de marquises. "Eu tive que alimentá-los e mantê-los ${ }^{14}$ " (informação verbal, tradução nossa).

O caso de Vargas é o mesmo de Sebastian Quintero, vendedor da revista há oito anos (Figura 3). "Sextas e sábados são os dias que vendo mais"15" (informação verbal). Quintero conta que há muitas mulheres que também são canillitas e que precisam do trabalho para sustentar seus filhos.

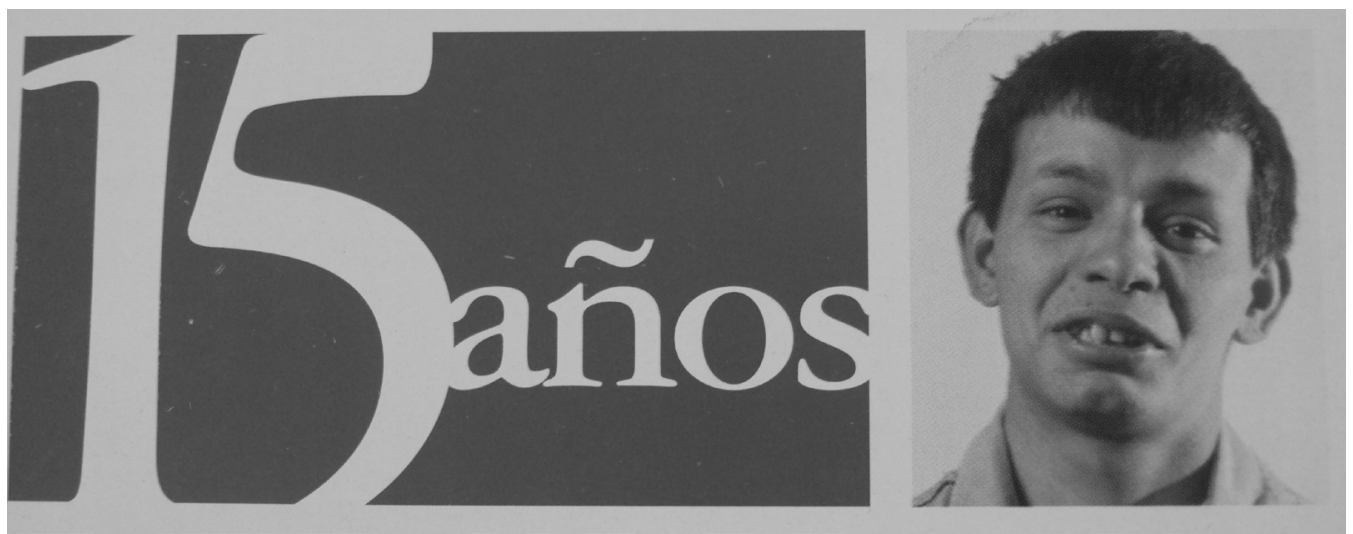

Figura 3: Sebastian Quintero é um dos canillitas que apareceram na capa de 15 anos da revista

Na edição especial de dez anos da revista, Laura Albertini (2005), colaboradora da Luciérnaga, explica como funciona o processo de transição de chicos de calle para canillitas (Figura 4):

Quando um jovem solicita ingressar [no projeto] averigua-se em que situação familiar ele se encontra, em que condições vive, quantas horas passa na rua e quantas mais pode dedicar-se a educação formal. O mais importante não é que ele venda muito, importa para quê vende, importa que possa pensar em um projeto de vida, ter um horizonte e sonhar com ele trabalhando para poder torná-los possível ${ }^{16}$ (ALBERTINI, 2005, p.10-1, tradução nossa).

14 Entrevista concedida à autora em 16 de junho de 2012, no centro da capital de Córdoba. 15 Entrevista concedida à autora em 8 de junho de 2012, no centro da capital de Córdoba. 16 Texto original: Cuando un joven solicita ingresar se averigua en qué situación familiar se encuentra, en qué condiciones vive, cuántas horas pasa en la calle y cuántas más puede dedicar a la educación formal. Lo más importante no es que venda mucho, importa para qué vende, importa que pueda pensar un proyecto de vida, tener un horizonte y soñar con él trabajando para hacerlo posible. 


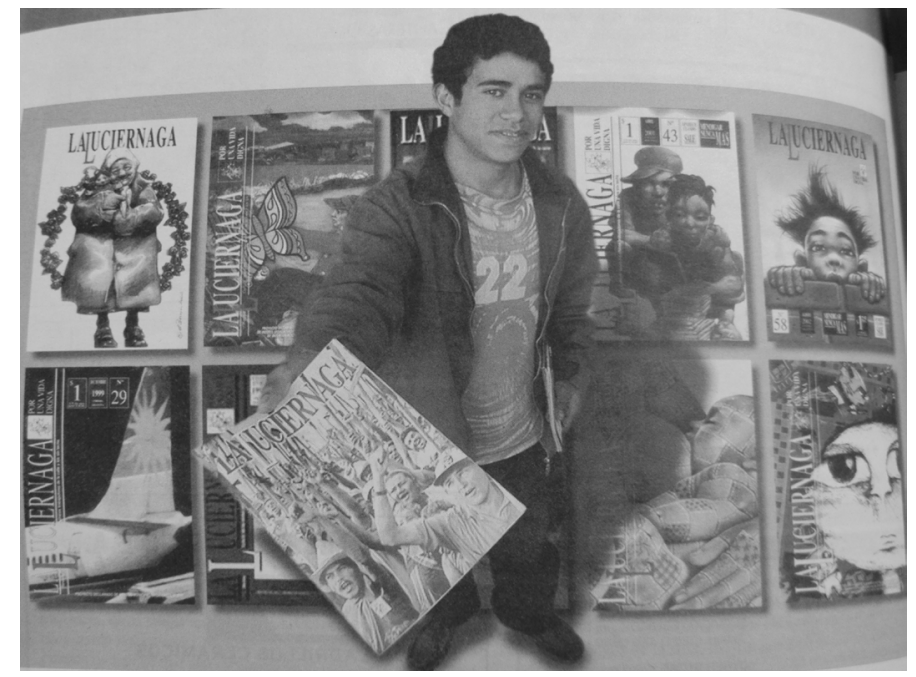

Figura4: Foto que ilustra o artigo da revista: um canillita com a edição n.69, de agosto de 2003, com os sem-terra brasileiros na capa.

Sob a ótica da autora, enquanto os meninos desempenham a função de canillita, a rua se torna uma oportunidade de trabalho digno e de múltiplas aprendizagens, mas, se não houver um crescimento pessoal, depois de um tempo, essa mesma rua começa a desgastar e a repetir as frustrações de antes. Por isso, depois de completar um ciclo de trabalho, aos que têm bom comportamento são oferecidas vagas de trabalho em outros setores, já que os próprios empregadores pedem indicação de perfis na Fundación La Luciérnaga. Assim, precisam se adaptar aos novos horários, desvincular-se de hábitos de rua, aceitar a figura hierárquica do patrão e administrar o salário durante trinta dias.

\section{CONSIDERAÇÕES FINAIS}

A revista e a Fundação La Luciérnaga, ao surgirem devido a um descumprimento do Estado, acabam cobrindo uma lacuna do governo argentino, pois criam condições para que jovens em situação de risco social obtenham renda de maneira legal, através da venda das revistas, além de serem inseridos socialmente pela cultura do trabalho.

Depois de 17 anos de existência, a publicação favoreceu a reconstrução da opinião pública acerca dos meninos de rua por meio de sua metodologia e conteúdos, reduzindo as ideias-imagens herdadas do século passado, que associam os canillitas a meninos infratores.

Outro ponto que merece destaque é o fato de estimularem os luciérnagos aos estudos e inserirem os que têm bons comportamentos em empregos formais. Nessa práxis, o projeto desempenha seu objetivo de fazer 
com que os jovens "fabriquem sua própria luz" e transcendam sua condição social e econômica por meio de seus próprios esforços.

Em relação ao conteúdo jornalístico, a publicação se apresenta como um espaço valioso, onde divulga, dentre outras coisas, assuntos polêmicos, que nem sempre são cobertos pela grande mídia, além de ouvir como fontes pessoas marginalizadas.

A aliança com universidades argentinas e escritores renomados é uma estratégia que colabora para o sucesso da revista. No entanto, para que os canillitas sejam realmente considerados protagonistas e trabalhem de forma coletiva, como destaca o fundador do projeto, deveria haver uma seção fixa em que eles tivessem autonomia desde a escolha do conteúdo até a edição do material a ser publicado. Tal prática não diminuiria a qualidade do produto, serviria apenas para legitimar a revista cultural de los chicos trabajadores de la calle.

\section{REFERÊNCIAS}

ALBERTINI, Laura. Cuando el trabajo dignifica. In: La Luciérnaga. n. 93, 2005, p.10-13 ALBRECHT, Roxana. La Luciérnaga, revista de los chicos de la calle. Del cambio social a la empresa social. Trabalho de Conclusão de Curso (Curso de Ciências da Comunicação)Universidade Nacional de Buenos Aires, Buenos Aires, 2009.

ARIAS, Oscar. [Entrevista concedida à autora.]. Córdoba. 20 jun. 2012.

AVERSA, María Marta. Vagos, mendigos y delincuentes: La construcción social de la infancia peligrosa. Buenos Aires, 1900-1910. In: Cuadernos del Sur. Historia. n.32. Bahía Blanca, 2003. Disponível em: <http://bibliotecadigital.uns.edu.ar/scielo.php?script=sci arttext\&pid=S1668-76042003000100001\&lng=pt\&nrm=iso\&tlng=pt $>$. Acesso em 24 jul. 2012.

HANKS, Sinead; SWITHINBANK, Tessa. The Big Issue and other street papers: a response to homelessness. In: Environment and Urbanization, vol. 9, No. 1, abr. 1997. Disponível em:< http://eau.sagepub.com/content/9/1/149.full.pdf+html>. Acesso em: 29 ago. 2011.

INGENIEROS, José. Los niños vendedores de diarios en nuestra delincuencia precoz. Anais do Patronato da Infância, Ano XIII, tomo XIII, Buenos Aires, 1904.

LA LUCIÉRNAGA. Diez años de luz. n. 93, 2005, p.5.

LAGE, Nilson. Teoria e técnica do texto jornalístico. Rio de Janeiro: Elsevier, 2005, pp.1935.

QUINTERO, Sebastian. [Entrevista concedida à autora.]. Córdoba. 8 jun. 2012.

SODRÉ, Nelson Wernek. História da imprensa no Brasil. 4. Ed. Rio de Janeiro: Mauad, 1999.

SOUSA, Jorge Pedro. Uma breve história do jornalismo no Ocidente. In: SOUSA, Jorge 
Pedro. Jornalismo: história, teoria e metodologia. Porto: UFP: 2008. Jornalismo: história, teoria e metodologia. Porto: UFP: 2008, p. 12-92.

TRENTO, Angelo. Do outro lado do Atlântico: um século de imigração italiana no Brasil. São Paulo: Nobel, 1989.

TROCELLO, Luciana. Ustedes, los lectores. In: La Luciérnaga. n. 93, 2005, p.21.

VARGAS, Emanuel. [Entrevista concedida à autora.]. Córdoba. 16 jun. 2012. . Soy Emanuel Vargas. In: La Luciérnaga. n. 176, 2012, p.5.

VELASCO, Rafael. Por qué La Luciérnaga? In: La Luciérnaga. n. 170, 2011, p.3.

\section{Suzana Rozendo Bortoli}

Formada em Comunicação Social com habilitação em Jornalismo pela Universidade Federal de Mato Grosso do Sul (2008), mestre em Jornalismo pela Universidade Federal de Santa Catarina (2012) e doutoranda do PPGCOM/ECA/USP (Brasil).E-mail: suzanarozendo@usp.br 